\title{
Developing Students' Cognition Culture for Successful Foreign Language Learning
}

\author{
Lyubov Pavlova ${ }^{1, *}$ and Yuliana Vtorushina $^{1}$ \\ ${ }^{1}$ Nosov Magnitogorsk State Technical University. Magnitogorsk. Russia
}

\begin{abstract}
This paper presents results of the research aimed at determining essential aspects of the development of university students' cognition culture as a factor of successful foreign language learning. The authors define cognition culture as a complex of capabilities and skills, enabling students to look for, analyze, process, organize and critically assess information in the text, considering its historical and cultural value background. The investigation proves that a student's cognition culture is manifested in his/her knowledge of national mentality, language, and cultural picture of the world as well as in the student's skills of search, procession and critical assessment of information, the skills of analysis, comparison, generalization, cognitive motivation and aspiration for constant improvement of foreign language skills. The research determines the contents of the cognitive component of foreign language learning and works out a complex of teaching techniques for developing students' cognition culture. The results prove that the application of the complex of special teaching techniques ensures effective development of the university students' cognition culture for successful foreign language learning. Thus, students' cognitive culture conditions their social adaptation and academic mobility.
\end{abstract}

\section{Introduction}

The cognitive function of foreign language is connected with cognitive aspects of a person's development. It is common knowledge that language is an instrument of communication and cognition, so knowledge is a result of a cognitive process. Psychologists and linguists maintain that there are internal cognitive mechanisms, which condition the formation of linguistic concepts. It has been noted that the process of the formation of linguistic knowledge resembles the concept formation process. L.S. Vygotsky [1], P.Y. Galperin [2], E. Kubryakova [3] pointed at the resemblance of cognitive mechanisms in the process of concept formation and a person's linguistic development. These papers deal with native language research, which acknowledges parallelism of a person's linguistic and cognitive development. Foreign language mastering is realized in other ways than it was with the native language acquisition. In this case, a person's linguistic and cognitive development is not parallel, as his/her cognitive development has already been achieved in many ways. But both the processes basically concern the same kind of processes of speech development and are closely interrelated with each other.

The process of forming a linguistic concept in a foreign language is similar to that in the native language. It includes the following steps: concrete experience (a student is confronted with a new linguistic notion and shown its functions), observation, reflection, abstract conceptualization (formation of the initial idea of the linguistic notion), experiment (first attempts to use it in speech), correction. This cognitive scheme manifests the universal nature of a person's cognitive activity while studying a foreign language. However this general process is realized individually by every person. It can be done with the help of individual cognitive techniques and cognitive, social, affective strategies [4].

The actuality of the research is caused by the necessity of modernization of university linguistic education whose main goal is to prepare competitive specialists in the field of different tasks' effective solving, to prepare people who are capable to communicate on the intercultural level, striving for constant self-perfection and self-education in the sphere of language. The research determines essential aspects of the cognitive development process through foreign language learning, which is manifested in a person's cognition culture.

\section{Materials and methods}

For accomplishing the designated tasks, the following research methods were used: theoretical methods (analysis, interpretation and generalization), empiric methods (observation, interviewing, questioning, testing, experiment), data processing methods (statistic data processing methods, computer processing methods and data presentation methods)

* Corresponding author: pavlovaluba405@mail.ru 


\section{Discussion}

The research theoretical and methodological basis is as follows:

- socialization and social development theories (G.M. Andreyeva, L.P. Buyeva, I.S. Kon, A.V. Mudrik, A. Maslow, A.V. Petrovsky etc.) ;

- personality formation and cognitive development theories (B.G. Ananyev, L. S. Vygotsky, P.Y. Galperin, A. N. Leontyev, I.Y. Lerner, V.N. Myasishev, K.K. Platonov, S.L. Rubinstain, A.M. Shakhnarovitch etc.);

- methods of teaching foreign languages (M.A. Ariyan, I.L. Bim, N.D. Galskova, N.I. Gez, I.I. Khaleeva, E.I. Passov, A.N. Shamov, A.V. Shepilova, E.N. Solovova, H.D. Brown, G.F. Brumfit, J. Harmer, K. Morrow, W. Rivers etc.).

According to A.V. Shepilova, a foreign language learner, while studying a foreign language, goes through some natural phases of the cognitive process, including analysis or recollection of the previous knowledge in a particular sphere, observation of a new problem, discovery of the contradiction between old and new knowledge, ascertaining inadequacy of old knowledge, experimental usage of new knowledge and a new spire of correction of the new knowledge [4].

Thus, the process of foreign language learning develops a person's own mental structures, which not only contribute to successful mastering of the foreign language, but also enrich the learner's cognitive sphere and cognitive skills, and increase the quality and productivity of his/her cognitive activity. By studying a foreign language, a student learns different ways of expressing his/her thoughts, which improves the knowledge of native language. A foreign language serves as a standard of comparison with the native language and gives learners the opportunity to realize the fact, that there are some other different correlations between form and meaning.

In this cognitive process of comparing one's native language with a foreign language, there are the following components of man's language ability perfect: analysis, comparison, synthesis, generalization, classification, transfer, speech surmise. These operations are universal and testify to a personality's cognitive development.

The cognitive function of foreign language is connected with the following categories as knowledge, thinking, understanding, which operate in the process of language acquisition. Language knowledge, which is conditioned by a society's cultural norms and values, and interpreted by a person's consciousness, becomes personal and functions in the context of a person's own varied experience. To recognize a word means to involve it in the context of the previous experience. The inner context is connected with individual knowledge, individual person's picture of the world. In the process of forming an individual person's picture of the world, learners rely on: 1) the cognitive means of their native culture, which are drawn in order to help them understand a new culture; 2) on new knowledge about a foreign culture, acquired in the process of its cognition; 3 ) on new knowledge of their native culture, acquired in the process of cognition a foreign culture. The knowledge, which is used while coding and decoding a message, is not limited to language knowledge only. The totality of knowledge about the word, social context of an utterance, discourse (the rules of its planning and peculiarities) allows a person to perceive and understand mentality and spiritual life of the people, who speak target language and is a competent speaker [5]. Hence, the goal of teaching cross-cultural communication is in the learner's acquiring new linguistic and cultural knowledge which would correlate with the knowledge about the world of the representative of another sociocultural community. This knowledge constitutes fragments of the linguistic and conceptual picture of the world, which is directly connected with associative verbal net of the language.

In the process of foreign language learning basic cognitive structures are formed in a learner's consciousness. These structures ensure a learner's perception and understanding another language and another society as another sociocultural community. The process of forming basic cognitive structures enriches in a learner's consciousness the links between the elements of assimilated linguistic cultures. So, foreign language learning causes changes in a person's cognitive activity and conditions his/her cognitive development [5].

Sharing this opinion, it is worthwhile to notice that in the process of foreign language learning a person's cognitive culture not only secures his/her ability to understand another mentality, other social values, but also develops an ability to accumulate foreign cultural social experience, master the ways of cognizing the surrounding world, and develop linguistic creative thinking. Understanding another culture is a complicated, many-sided process of understanding other sociocultural phenomena. Besides, understanding involves not only data processing and interpretation, but activation and use of inner cognitive information, i.e. the information about cognitive presuppositions. The perception and understanding of an authentic text is conditioned by the interaction between the structure and semantics of the text and also between a person's consciousness and memory. Understanding, being a complicated cognitive process, implies not only a verbal text, but also background cultural knowledge, which imparts certain inferences and implications. Moreover, cognitive motives and cognitive activities are of utmost importance, as they are the main means of developing a learner's individual picture of the world, in the basis of which there is knowledge about the world and knowledge from other fields, inherent to another culture, or universal knowledge.

So we may conclude that understanding is a two-way process, in which a person, perceiving this or that sociocultural phenomenon, does not just passively builds up some language image, but actively interprets it. New opinions and purposes, which are growing up in the process of understanding, are formed on the basis of a learner's personal social experience, generalizations and fixed associations [6].

When new sociocultural images confront images of the native linguistic culture, a foreign language learner develops a new way of perception and cognition of the 
surrounding world and perfects language mechanisms of knowledge acquisition, ways of representing objective reality, worked out by another culture. In this synergy of language, consciousness and culture, interrelation and interdependence of cognitive and communicative personal development processes the opportunities of a foreign language learner's cognitive development become evident. These generalizations are very acute for our research, because the process of education, cognition and culture acquisition never ends. So, the main task of an educational institution nowadays is to prepare specialists capable of studying throughout their whole life and willing to learn languages and cultures [7].

The modern theory of language learning is based on a student-centered approach and claims as its main goal harmonious development of a personality, which ensures a person's abilities of cognition of the surrounding world and interaction with other people [8]. Hence, we may allege that the cognitive component of foreign language learning must comprise : knowledge of cultural concepts, lying in the basis of a foreign cultural picture of the world; knowledge of the national mentality; skills to communicate and interact according to international etiquette and social norms, accepted in this particular society; knowledge of the universals of culture and their contents in different cultures; the ways of reflection culture in language and in oral intercourse; knowledge of stereotypes, prejudices and generalizations, ways of regulating a person's emotions; skills of empathy; knowledge of psychological peculiarities of intercultural communication.

Moreover, association with a system of values of another culture is connected with understanding, realization and forming one's personal attitude to new values, socio-cultural knowledge, i.e. with the process of reflection. Thus, the development of reflective abilities becomes of great importance, as the acquired social experience of a new culture is considered from the point of view of its importance, novelty, actuality and conformity with the person's own values, aims and motives. The above-mentioned reflective abilities contribute to a person's development of his/her set of values, which becomes a basis for one's conscious striving for cognition and self-perfection.

Under these circumstances, a learner's active personal attitude to acquired knowledge and skills of foreign language learning means that the main goal of the language education is a permanent process of selfperfection, aimed at developing skills of eliciting, processing, organizing and using new information for one's own constant self-education.

So, on the basis of the analysis of the relevant research, theoretical and practical data cognition culture is defined as a complex of capabilities and skills, which make it possible firstly to look for, analyze, process and organize information; secondly, to critically assess information in the text, considering its historical and value background. A student's cognition culture is manifested in his/her knowledge of national mentality, language, cultural and conceptual picture of the world. It is also presented in the student's skills of search, procession and critical assessment of the information as well as in the student's skills of analysis, comparison, generalization, cognitive motivation and aspiration for constant improvement of a foreign language. What is more, a person's cognitive culture conditions his/her social adaptation, mobility, stability and insures his/her success in different spheres of life [6].

On the basis of the research data and teaching practice we determined teaching techniques, aimed at developing university students' cognition culture in the process of foreign language learning. They are as follows: social cultural information transfer, social cultural information gap, sociological poll, social cultural information ranging, value analysis of works of culture, project work on comparing electronic and printed mass media.

The peculiarity of social cultural information transfer is that the perception and assimilation of the information is gained in the process of the transfer of the information from one form into another (graphic into verbal, and vice versa). The student has to perform a series of actions: process graphic information, extract verbal means from memory, involve them into the mental scheme.

Social cultural information transfer allows acquainting students with various ways of visual representation of political, economic and sociocultural aspects of life of the country of the target language. As a result, the student not just reproduces sociocultural information (the level of reproduction), but solves a problem task, which makes him motivated, and stimulates his creative activity.

Social cultural information gap stimulates students' cognitive activity, which is selectively aimed at getting new sociocultural information. The information must be of cognitive value and must meet students' individual interests and goals.

Sociological polls also help to develop students' cognitive skills. The students learn to make adequate questionnaires, get necessary information, process and generalize the obtained information, make cultural commentaries in which they analyze the respondents' answers considering their hierarchy of values.

Social cultural information ranging is based on students' differences in values when they range some cultural information. This technique activates learners' personal experience, helps to foster values and realize one's own motives and goals and contributes to understanding universal human values.

Value analysis of works of culture is aimed at exploring a value system, shared by the representatives of the culture of the target language, making personal estimates of the revealed values, realization of students' own common and different values, forming one's personal attitude to new values $[9,10]$. This technique is employed in the process of text analysis and text interpretation. In the course of the research, we worked out the following stages of value analysis of the text:

1 - preparatory-motivation stage - which is designated to acquaint students with structural and language peculiarities of the genre of the text under analysis, activation and correction linguistic and cultural knowledge and gaining new knowledge, which is necessary for understanding the text; 
2 - analytical-perceptive stage - which is aimed at grasping factual information: the plot and composition of the text and analyzing linguistic units, which have national cultural component; exploring values: i.e. identifying the hero of the text, the moral or the main idea of the text, characterizing the hero's behavior (approved or condemned); formulating the meaning of the explored value;

3 - value fostering stage - which has as its purpose deep understanding of the text and generalizing linguistic and cultural knowledge; gaining students' knowledge about cultural concepts and moral values lying in the basis of the foreign cultural picture of the world; defining the role of values in regulating and assessing a person's behavior; forming personal estimates of these values: comparing one's own opinion with the characters' opinions; discussing values in the context of the target language culture and realizing one's own shared or different values; comparing the explored values with the national value system and turning to the universal values.

So, the technique of value analysis of works of culture ensures understanding of the social behavior from the point of view of another culture, contributes to the students' realizing their own cultural identity and assimilating universal values.

Students' autonomous research activities considerably facilitate their cognitive development. As a matter of fact, autonomous research work is regulated and managed by a student on his/her own, and it is aimed at gaining sociocultural knowledge, skills and social experience. The autonomous research work on the Internet is carried out by studying information resources and performing problem-research web tasks. Students make search of necessary materials, assess the quality of the information, learn to interpret, process and represent the information adequately, thus developing their information competence. They may widely use such resources as Hotlist, Multimedia Scrapbook, Treasure Hunt, Web Quest etc. Project work can serve as an example of autonomous investigative activity as well, because web-projects also contribute to creative and research aspects of teaching foreign languages. The webproject goes through the following stages: defining of the problem, making hypotheses, searching for and studying necessary information on the Internet, analysis and group discussion of the collected materials, synthesis and summing up the information, group discussion and choice of the way of presenting the obtained results. Group work, autonomous search and selection of the information, group discussions, distributing responsibilities promote students' development of communicative skills, make it possible to investigate different phenomena from different angles, make one's own point of view of current events, taking place in the world, express one's opinion in a creative way.

The observed teaching techniques develop the skills of eliciting values from an authentic text, comparing these values with the ones of the native culture, skills of finding similarities and differences between the native and foreign culture, skills of finding universal values, which can unite different cultures. Thus, these teaching techniques stimulate learners' cognitive, communicative development and ensure their cognitive strategies and gaining social experience.

\section{Results}

The experimental work comprised two stages: a verifying experiment was carried out on the basis of three universities: Magnitogorsk State University (MaSU), Nosov Magnitogorsk State Technical University (MSTU), Glinka Magnitogorsk State Conservatoire (Academy of music) (MaSC) with 900 students, taking part in it; and modelling experiment, which was conducted in MSTU, involving 197 students. In the course of the verifying experiment we used as the main diagnostic tool the test "Technology of eliciting and processing information" (after J. Sergayeva) [6], and questionnaire on students' readiness for constant selfeducation. It was established that $35 \%$ of students in the experimental group $1 ; 34 \%$ of students in the experimental group 2 ; consequently $33 \%$ of students in the experimental group 3; and $32 \%$ of the respondents in the control group displayed a low level of cognition culture skills. About $24.3 \%$ of students of experimental groups 1, 2, 3 on average; and $25 \%$ of the students in the control group proved the medium level. The number of students on the high level is a little bigger in the control group $(18 \%)$, whereas in the experimental groups the number of students on the high level equals on average $16.3 \%$.

The measurements showed that students had difficulties in eliciting obvious and hidden information from texts and making a synopsis of mass media texts. The reproduction of factual information did not cause evident difficulty. The critical estimation of the elicited information as to its trustworthiness or falsity, objectivity and subjectivity turned out to be the most difficult task. The students' multimedia presentations showed their inadequate level in the field of information technologies application for eliciting and comparing information from mass media.

So, the preliminary data of the verifying experiment proved that practically no specific differences between the experimental and control groups were registered before the modelling experiment. On the whole, the results of the verifying experiment proved the actuality of the formation of students' cognition culture skills.

Table 1 shows the results of the modelling experiment, which was carried out in order to test the effectiveness of the complex of teaching techniques aimed at developing university students' cognition culture in the process of foreign language learning.

At the end of the modelling experiment, on average $34.3 \%$ of students in the experimental groups displayed a high level of cognition culture skills, only $12.6 \%$, of students remained on a low level, and $53 \%$ displayed a medium level of cognition culture skills.

The comparison of the verifying experiment and modelling experiment data showed that on average the number of students with a high level of cognition culture skills multiplied by 2.1 and consequently the number of 
students with a low level of cognition culture skills decreased by 2.6 in the experimental groups, whereas in the control group we did not register any significant increase in the number of students on the high level.

Table 1. Comparison of modelling experiment's results with regard to the change of the students' cognition culture skills level.

\begin{tabular}{|c|c|c|c|c|c|c|c|}
\hline \multirow{3}{*}{$\begin{array}{l}\text { Groups } \\
\\
\begin{array}{l}\text { EG-1 } \\
\text { (Start) }\end{array}\end{array}$} & \multicolumn{6}{|c|}{ Levels } & \multirow{3}{*}{$\begin{array}{l}\begin{array}{l}\text { Number } \\
\text { of } \\
\text { people }\end{array} \\
49 \\
\end{array}$} \\
\hline & \multicolumn{2}{|c|}{$\begin{array}{c}\text { Low/ } \\
\text { Number } \\
\text { of people } \\
\%\end{array}$} & \multicolumn{2}{|c|}{$\begin{array}{c}\text { Medium/ } \\
\text { Number } \\
\text { of people } \\
\%\end{array}$} & \multicolumn{2}{|c|}{$\begin{array}{l}\text { High/ } \\
\text { Number } \\
\text { of people } \\
\%\end{array}$} & \\
\hline & 17 & $35 \%$ & 24 & $49 \%$ & 8 & $16 \%$ & \\
\hline $\begin{array}{l}\text { EG-1 } \\
\text { (Fin) }\end{array}$ & 7 & $14 \%$ & 26 & $53 \%$ & 16 & $33 \%$ & 49 \\
\hline $\begin{array}{l}\text { EG-2 } \\
\text { (Start) }\end{array}$ & 17 & $34 \%$ & 25 & $50 \%$ & 8 & $16 \%$ & 50 \\
\hline $\begin{array}{l}\text { EG-2 } \\
\text { (Fin) }\end{array}$ & 7 & $14 \%$ & 26 & $52 \%$ & 17 & $34 \%$ & 50 \\
\hline $\begin{array}{l}\text { EG-3 } \\
\text { (Start) }\end{array}$ & 16 & $33 \%$ & 24 & $50 \%$ & 8 & $17 \%$ & 48 \\
\hline $\begin{array}{l}\text { EG-3 } \\
\text { (Fin) }\end{array}$ & 5 & $10 \%$ & 26 & $54 \%$ & 17 & $36 \%$ & 48 \\
\hline $\begin{array}{l}\text { KG } \\
\text { (Start) }\end{array}$ & 16 & $32 \%$ & 25 & $50 \%$ & 9 & $18 \%$ & 50 \\
\hline $\begin{array}{l}\text { KG } \\
\text { (Fin) }\end{array}$ & 15 & $30 \%$ & 26 & $52 \%$ & 9 & $18 \%$ & 50 \\
\hline
\end{tabular}

As a result of experimental teaching, the students of the experimental groups displayed a higher level of knowledge of the language, cultural and conceptual picture of the world and the skills of finding national and cultural specific values in the native and a foreign culture. All the students (94\% in experimental groups and consequently $86 \%$ in the control group) showed approximately the same level of skills of finding cultural information in texts, dialogues, characters' actions (for example: global problems, healthy way of life, feminism, vegetarianism, political correctness and so on), whereas only the students of experimental groups showed the high level of skills of critical thinking, critical assessment of the information with regard to its trustworthiness/ falsity, objectivity/subjectivity and skills of commenting on the language persuasion and evaluation means, and also means of expressing bias in the text, considering its historical and cultural value background.

Besides, the students of the control group experience considerable difficulties in comparison and analysis of English/American and Russian cultural and language picture of the world and text interpretation while performing the tasks, concerned with value analysis of works of culture. Moreover, the students of experimental groups displayed a considerably higher level of skills of search, procession and critical assessment of the information than the students of the control group, which is connected with the intensive use of multimedia and project work on comparing electronic and printed mass media in experimental groups.
It is worthwhile noticing that the most significant increase in students with the high level of cognition culture skills takes place in experimental groups 2 and 3 , as the number of such students multiplied by 2.1. The absolute growth with regard to the high level consequently reaches $18 \%$ and $19 \%$. The most essential decrease in the number of students with a low level of cognition culture skills (by 3.2 times) is registered in experimental group 3 , and the total absolute growth with regard to the medium + high level equals $23 \%$ of students. So the total absolute growth with regard to the cognition culture skills criterion in the experimental group 3 is $21 \%$ more than that in the control group

\section{Conclusion}

The complex of teaching techniques, aimed at developing university students' cognition culture in the process of foreign language learning comprises: social cultural information transfer, social cultural information gap, sociological poll, social cultural information ranging, value analysis of works of culture, project work on comparing electronic and printed mass media. The obtained results prove that the application of the complex of special teaching techniques ensures effective development of the university students' cognition culture as a factor of successful foreign language learning.

\section{References}

1. L. Vygotsky, Thinking and speaking (Labirint, Moscow, 1999)

2. P. Galperin, Introduction to Psychology (Moscow University Press, Moscow, 1976)

3. E. Kubryakova, L. Saharny, A. Shakhnarovitch, Speech development in the context of psychic development. Human factor in language (Nauka, Moscow, 1991)

4. Shepilova, Foreign languages in school 2, 4-12 (2003)

5. N.D. Galskova, N.I. Gez, Theory of foreign language teaching: manual for university students (Academy, Moscow, 2015)

6. L. Pavlova, Humanitarian culture developing foreign language university education (Flinta: Nauka, Moscow, 2015)

7. L.I. Savva, N.Ya. Saigushev, O.A. Vedeneeva, L.V. Pavlova, E.I. Rabina, Student's time awareness formation: self-organized personality as promoting factor for mental health, The European Proceedings of Social \& Behavioral Sciences EpSBS XXVI, 858-864 (2017)

8. M. Ariyan, Foreign languages in school 7, 2-8 (2008)

9. V. Safonova, Procedia - Social and Behavioral Sciences 154, 57-63 (2014)

10. O. Pustovalova, VGU Herald. Series: Linguistics and intercultural communication 1, 109-113 (2004) 